\title{
Análise Pluviométrica do município de Poços de Caldas-MG usando a metodologia de Anos-Padrão
}

\author{
Pluviometric Analysis of the municipality of Poços de Caldas-MG using the Standard-Years \\ methodology
}

\author{
Matheus Lima de Andrade \\ Mestrando em Geografia na UNIFAL-MG, Alfenas-MG, Brasil \\ matheusgsmer@gmail.com \\ Thomaz Alvisi de Oliveira \\ Doutor em Geografia pela UNESP. \\ Professor Adjunto do IFSULDEMINAS, Poços de Caldas-MG, Brasil \\ thomaz.oliveira@ifsuldeminas.edu.br \\ Bruno César dos Santos \\ Doutorando em Ciências da Engenharia Ambiental da EESC/USP, \\ São Carlos- SP, Brasil \\ bruno-unifal@hotmail.com \\ Gabriel Flora Vieira \\ Mestrando em Geografia na UNIFAL-MG, Alfenas-MG, Brasil \\ gabrielflora844@gmail.com \\ Allan Carlos de Andrade \\ Graduando em Geografia - PPGEO UNIFAL MG, Brasil \\ allan.andrade@sou.unifal-mg.edu.br
}

\section{Resumo}

O padrão climático de um dado local é influenciado por inúmeros fatores e elementos, que podem ser tanto naturais ou antrópicos. Os fatores e elementos naturais estão relacionados à expressão da topografia, à localização, ao posicionamento latitudinal, à presença de tipos vegetacionais característicos entre outros. Os elementos antrópicos são aqueles que, de alguma forma, alteram esse padrão climático, emissão de gases do efeito estufa. O município de Poços de Caldas contextualizado no Sul do estado de Minas Gerais apresenta particularidades relacionadas ao meio físico que impõem diferenciações climáticas importantes quando comparadas àquelas verificadas nos municípios circunvizinhos. A altimetria elevada com a presença de serras, o posicionamento latitudinal e a localização interiorizada, ou seja, mais distante da costa interferem na distribuição dos totais pluviométricos mensais e anuais bem como nas médias de temperatura. Sob essa ótica de análise, foi desenvolvido um estudo com o objetivo de identificar a habitualidade atmosférica do município nos últimos anos com base na metodologia de anos-padrão, analisando a precipitação a partir dos dados disponibilizados numa série de 16 anos disponibilizados pela Companhia Brasileira de Alumínio CBA e Departamento Municipal de Água e Esgoto - DMAE. Os resultados obtidos permitem destacar a delimitação de dois comportamentos atmosféricos, sendo o primeiro com constância pluviométrica, ou seja, onde a habitualidade é confirmada na média histórica, e o outro, com oscilação, exposto neste estudo através dos anos extremos que estão relacionados a eventos extremos de chuva ou seca.

Palavras chaves: Climatologia; Precipitação; Habitualidade; Dados; Atmosfera. 


\begin{abstract}
The weather pattern of a given location is influenced by numerous factors and elements, which can be either natural or anthropogenic. Natural factors and elements are related to the expression of topography, location, latitudinal positioning, and distinct vegetation types, among others. Anthropogenic elements are those that, in some way, change this climate pattern, emission of greenhouse gases. The municipality of Poços de Caldas, contextualized in the south of the state of Minas Gerais, presents particularities related to the physical environment that impose important climatic differences compared to those verified in the surrounding municipalities. For example, the high altitude with the presence of mountain ranges, the latitudinal position, and the interior location, that is, more distant from the coast, interfere in the distribution of monthly and annual rainfall totals and the average temperature. From this perspective of analysis, a study was developed to identify the atmospheric habitually of the city in the last years based on the methodology of standard years, analyzing the precipitation from the data available in a series of 16 years made available by the Companhia Brasileira de Aluminum - CBA and Municipal Department of Water and Sewage DMAE. The results obtained allow us to highlight the delimitation of two atmospheric behaviours, the first with constant rainfall, where habitually is confirmed in the historical average. The other, with oscillation, is exposed in this study through extreme years related to events extremes of rain or drought.
\end{abstract}

Keywords: Climatology; Precipitation; Habituality; Data; Atmosphere.

\title{
1. INTRODUÇÃO
}

Os sistemas da natureza estão presentes cotidianamente na vida do ser humano, impactando nos aspectos econômicos, políticos e socioambientais, como é o caso dos fenômenos climáticos que alternam aguaceiros e estiagens, associando-os eventualmente a temperaturas elevadas ou baixas que fogem muitas vezes à habitualidade atmosférica do lugar.

$\mathrm{Na}$ gênese climatológica se destacam os fatores e elementos do clima. Dentro destes se destacam a radiação, a pressão, a temperatura e a umidade, fatores dinâmicos que variam no tempo e no espaço de análise. Já aqueles são a latitude, altitude, maritimidade, continentalidade e a vegetação, massas de ar, correntes marítimas, e, relevo, aspectos que modelam e promovem nuances internas nos climas globais.

Outro fator que influencia de forma direta no clima são as intervenções antrópicas no espaço que produzem microclimas locais como as ilhas de calor, que são pontos de calor geralmente localizados nas grandes áreas urbanas, concentrando um grande excedente de calor comparado com o entorno periférico e rural. Nesse aspecto, Barros e Lombardo (2016, p.160) apontam que

[...] ambientes com ausência de vegetação, principalmente nos espaços ocupados por atividades industriais e de comércio e serviços apresentaram forte intensidade do fenômeno, com diferenças de temperaturas superiores a $8^{\circ} \mathrm{C}$, a temperatura varia de acordo com a realidade de cada município. 
Entender a atuação desses elementos climáticos é importante nos estudos da climatologia geográfica, pois possibilita a leitura do comportamento atmosférico e as tendências que vão sendo estabelecidas a partir das mudanças climáticas em curso no planeta.

Alguns métodos da climatologia geográfica podem determinar ritmos climáticos, variabilidades climáticas e até mesmo anos-padrão. Tais métodos são importantes para o estudo das variabilidades térmicas e de precipitações. Nos mesmos assumem importância os dados de superfície (estações meteorológicas), pois ajudam a ler o comportamento atmosférico por meio dos índices coletados que auxiliam na análise e compreensão dos ritmos climáticos.

A escolha de anos-padrão como forma de analisar a dinâmica atmosférica, teve início nas ideias de Monteiro (1973) que propôs critérios para a escolha de anos-padrão, a partir da análise rítmica, citada no estudo de Ogashawara (2012, p. 61) ao enfatizar que "A análise rítmica pode ser aplicada para estudos que possuam o objetivo de compreender a dinâmica da circulação atmosférica de superfície no que concerne aos seus impactos e/ou interações com os aspectos socioambientais pesquisados".

Atualmente têm se utilizado também os dados de satélites conjuntamente com a técnica linear de correção desses dados, uma vez que tais dados podem exibir informações diferentes daquelas apresentadas pelas estações meteorológicas. O intuito é aumentar a acurácia dos resultados.

Ataíde et. al (2009), por exemplo, avaliaram a temperatura de superfície obtida pelo sensor MODIS para o estado de Goiás. Na ocasião os autores (op. cit.) encontraram uma diferença média de $7,6^{\circ} \mathrm{C}$ nas leituras e temperatura quando comparadas às estações meteorológicas.

Com o advento da tecnologia proporcionada por satélites, cresceu o número de trabalho com dados dessa natureza, como é o caso dos dados de precipitação via satélite da NASA e JAXA, no caso o TRMM (Tropical Rainfall Measuring Mission), com a finalidade de monitorar e estudar os dados de precipitação tropicais; com isto, pesquisadores como Conti (2002), Araújo e Guetter (2005) compararam dados de precipitação de superfície com os dados de precipitação dos satélites nas pequenas e médias bacias do estado do Paraná, e concluíram que há uma aproximação entre os dados de superfície e de satélite. Os autores (op. cit.) pontuam que há um grande potencial com o uso de dados de satélites, já que pode ajudar na consistência dos dados, além de servir como ferramenta para análise de previsão hidrológica de uma bacia seja ela pequena ou grande.

No bojo das pesquisas da área climatológica, observa-se que o município de Poços de Caldas não possui estudos de anos-padrão e por este motivo torna-se importante determinar o padrão do sistema atmosférico pelos dados de precipitação, portanto, apresentar essa informação por meio de tabelas e análises permite exibir as oscilações pluviométricas no município, mediante a criação de classes de precipitação de acordo com o resultado da média e do desvio padrão da série adotada. 
Atentando para isto, o presente trabalho teve por objetivo definir os anos-padrão do regime pluviométrico do município de Poços de Caldas situado na porção Sul do estado de Minas Gerais, utilizando do método estatístico do desvio padrão para fazer uma classificação dos anos-padrão e delimitar os graus de variabilidade e habitualidade que se manifestam nesse momento de mudanças climáticas. Os dados utilizados nessa análise compõem uma série temporal histórica de 16 anos situados entre 2003 e 2018 que foram disponibilizados pela Companhia Brasileira de Alumínio - CBA e Departamento Municipal de Água e Esgoto - DMAE.

\section{DISCUSSÃO TEÓRICA}

Para a definição de um padrão climático em uma determinada região é preciso ter dados climatológicos de estações meteorológicas e os mesmos têm que estar em acordo com as normais climatológicas da O.M.M. (Organização Mundial Meteorológica, 1960) apud Instituto Brasileiro de Meteorologia (1999) que constitui o cálculo dos valores médios em um período que compreenda pelo menos trinta anos seguidos com dados disponíveis para análise.

No âmbito da Climatologia Geográfica brasileira temos poucos trabalhos utilizando AnosPadrão. Tal fato se explica pela ausência de dados ou pela falta de postos pluviométricos no país.

Segundo Tavares (1976), o uso da metodologia de Anos-Padrão para a análise rítmica da série histórica de dados climáticos, ajuda na padronização climática e no entendimento climático do local estudado. Tavares (1976) dividiu em 3 categorias os Anos-Padrões: normais, secos e chuvosos, que foram classificados mediante a porcentagem dos desvios padrões, variando de $<30 \% \mathrm{a}>30 \%$, em relação à média obtida na série de dados utilizadas na análise.

Neto (2000) analisou a tendência pluviométrica do Estado de São Paulo, compreendida em uma série histórica de 106 anos. O objetivo do autor foi procurar alterações significativas no comportamento pluviométrico no Estado. A metodologia se pautou na obtenção dos dados das estações pluviométricas, sendo a base histórica de dados de 1888 a 1993. Mediante a coleta de dados, o autor (op. cit.) formulou gráficos e tabelas para fundamentar seus resultados, salientando que a média da precipitação anual estava aumentando consideravelmente entre os períodos estudados. $\mathrm{O}$ estudo constatou uma tendência cíclica dos eventos extremos de precipitação do Estado de São Paulo.

Neves et al., (2011) desenvolveram um estudo baseado na modelagem climática regional em dois anos de extremos de precipitação no estado do Amapá. A região Norte não possui muitos postos pluviométricos, em razão disto foram usados, além dos postos pluviométricos, os dados de precipitação do Climate Prediction Center (2006 a 2007, compreendendo os meses de março, abril e maio) para mensurar a precipitação na região, no entanto, observou-se alguns desvios quando foi feita uma comparação com os resultados dos dados de superfície, principalmente na quantidade e na 
posição dos máximos dos dados obtidos. O método estatístico adotado foi o quantis, metodologia baseada em 5 intervalos de acumulação anual, sendo dividido em: muito seco (15\%), seco (15\% a $35 \%$ ), normal (35\% a 65\%), chuvoso (65\% a $85 \%$ ) e muito chuvoso (acima de $85 \%$ ). Diferente de outros autores já citados aqui, estes autores colocam que o quantis confere maior confiabilidade a dados de precipitação totais, por representar o verdadeiro significado do total pluviométrico.

Schneider et al., (2012) utilizaram o método de desvio percentual das precipitações para determinar a variabilidade de chuva no município de Dourados-MS, método este aplicado por Tavares (1976) que propôs o uso dos Anos-Padrão para, também, classificar o tipo climático de uma região. Dentre os resultados obtidos, os autores (op. cit.) chegaram na categorização dos anos extremos, que correspondem aos anos secos e chuvosos. Neste estudo 3 anos foram considerados chuvosos e 6 anos considerados secos mediante ao cálculo do percentual do desvio padrão. Os autores afirmaram a importância da metodologia de desvio padrão no estudo de variabilidade climática.

Nascimento et al., (2015) identificaram os Anos-Padrão do regime pluviométrico no Distrito Federal e no estado de Goiás e conseguiram contextualizar a dinâmica pluviométrica entre os anos de 1961 até 2012. Os Ano-Padrão seco, habitual, e, chuvoso foram identificados para as localidades por meio dos quantis como também foi utilizado no estudo de Neves et. al. (2011). Foram propostas três categorias para os quantis, sendo a divisão feita em: ano seco, ano habitual e ano chuvoso, baseandose na metodologia de Xavier (2002) na escolha de Anos-Padrões, que consiste em utilizar a metodologia estatística por meio do quantil na classificação que utiliza os dados do espaço amostral para organizar e separar os dados em subgrupos de análise, obedecendo o critério dos valores de precipitação anual totais distribuídos em sequência crescente e separados em subgrupos com valores iguais de amostras; com estes procedimentos foram identificados os Anos-Padrão de 2007, 2008 e 2009, que correspondem respectivamente aos anos com baixa pluviosidade, média pluviosidade e alta pluviosidade.

Santos et al., (2017) caracterizaram a precipitação do ano hidrológico de 2013-2014 na região de São Carlos-SP, comparando as precipitações do referido ano hidrológico com a distribuição sazonal da precipitação hidrológica de 21 anos. Os métodos adotados para a formulação da tabela dos Anos-Padrão, foram a média da precipitação anual e o desvio padrão, presentes também nos trabalhos de Farias e Alves (2019), Nascimento et al., (2015) e Schneider et al., (2012). Com os dados previamente preenchidos na tabela, o padrão de precipitação do município de São Carlos-SP foi dividido em 3 categorias de classificação (Normal, Seco ou Chuvoso). Na análise da série histórica, os valores dos desvios padrões apresentaram um comportamento maior dos anos habituais ou normais, ou seja, dentro da média da série histórica de 21 anos, no entanto, o ano hidrológico (2013/2014) apresentou um comportamento de desvio padrão negativo, superior a $-30 \%$, logo sendo 
um ano hidrológico classificado como anos secos, isto ocorre quando o desvio é negativo e muito abaixo da média histórica anual.

Souza et al., (2018) estudaram a frequência de ocorrência de precipitação pluviométrica em Montes Claros-MG entre os anos de 1995 e 2014. Os métodos estatísticos, utilizados para a formulação da tabela de precipitação, foram os dados máximos e mínimos para o cálculo dos percentis, a média mensal e anual e o desvio padrão, além de utilizar uma técnica de Box Plot, que oferece maior confiabilidade aos dados analisados. A técnica se resume na "determinação do menor e maior valor da série (mínimo e máximo, respectivamente), do primeiro e terceiro quartis e da mediana" (SOUZA, 2018, p. 338). O resultado do estudo, mostrou que o ano de 2008 foi considerado o de maior índice de precipitação da série histórica, apresentando $1.360 \mathrm{~mm}$. Já o ano com a menor precipitação foi o ano de 2014 com $478 \mathrm{~mm}$.

Farias e Alves (2019) desenvolveram um estudo sobre a distribuição espacial e temporal da precipitação na Costa Verde Fluminense, entre os anos de 2001 e 2016, cujo objetivo foi formular tabelas e mapas para mostrar a distribuição pluviométrica na região. Para a elaboração da tabela, foi utilizada a média dos 12 postos pluviométricos da região. Com estes dados médios das estações foi possível montar mapas temáticos, mostrando a precipitação média entre os anos de 2001 e 2016 . O desvio padrão ajudou a classificar a precipitação da região em anos chuvoso e seco.

Pelo que os estudos citados demonstram, a ausência de dados dificulta o desenvolvimento de pesquisas dessa natureza, fato que se observa no município de Poços de Caldas pela ausência de uma série histórica devido a quase inexistência de postos pluviométricos espalhados pelo município. Além disso, muitos dos postos pluviométricos existentes são de responsabilidade privada, o que dificulta o acesso. Muitas vezes os contatos com essas empresas privadas só são feitos por e-mail ou telefonema, quase sempre com muita morosidade para a obtenção dos dados. Em face disto, nesta pesquisa são utilizados dois postos pluviômetros privados de responsabilidade respectiva da Companhia Brasileira de Alumínio e do Departamento de Água e Esgoto de Poços de Caldas-MG.

No ano de 2016, no mês de janeiro, houve um evento extremo no município, que colaborou para uma inundação do centro da cidade. Segundo o Departamento Municipal de Eletricidade - DME (2016), precipitou em 2 horas $122 \mathrm{~mm}$, sendo que o esperado para o mês era $145 \mathrm{~mm}$, ou seja, o volume de chuva foi muito alto pelo pouco espaço de tempo que ocorreu, em termos estatísticos precipitou 97\% da média mensal em duas horas de chuva. No mesmo ano deste evento extremo, a Prefeitura municipal instalou na cidade 7 postos pluviométricos, em pontos estratégicos para a averiguação diária, mensal e anual da precipitação. No entanto não há disposição do poder público em compartilhar os dados coletados, dificultando o desenvolvimento de análises climatológicas que poderiam auxiliar na produção de informações úteis a toda coletividade local. 
A falta de dados nos postos pluviométricos, recobrou a adoção de métodos que auxiliam no preenchimento das lacunas de dados. Obviamente agrava-se a dificuldade de pesquisa se a falta de dados se estender por um período grande dentro da série histórica, como é o caso de muitos postos pluviométricos instalados no Brasil. Por isto são adotadas técnicas utilizando satélites para a mensuração prévia de precipitação, como é o caso do estudo de Neves et al., (2011), cuja área de estudo era o Amapá, apresentando um baixo número de postos pluviométricos.

Alberti (2008) desenvolveu um estudo buscando compreender as características fisiográficas da bacia do Ribeirão das Antas do Planalto de Poços de Caldas. Dentre os aspectos analisados e interpretados estão os dados de precipitação mensal. O enfoque dos dados de precipitação é diferente da pesquisa de Anos-Padrão, já que os objetivos são diferentes. O estudo do Alberti (2008) utilizou os dados de precipitação para analisar os aspectos físicos hidrológicos da bacia do Ribeirão das Antas, assim conseguindo determinar os valores de evapotranspiração e deflúvio da bacia.

A pesquisa envolvendo Anos-Padrão se pauta na gênese climatológica do município de Poços de Caldas-MG, utilizando-se os dados de precipitação para uma classificação do padrão de precipitação do município em uma série histórica que compreende os anos de 2003 a 2018. Obtendo a tabela de Anos-Padrão para analisar a oscilação do padrão de precipitação e propor um padrão de precipitação ao município.

\section{MATERIAIS E MÉTODOS}

\section{1. Área de Estudo}

O município de Poços de Caldas está localizado na região Sul/Sudoeste de Minas Gerais, limita-se na porção oeste com o estado de São Paulo. A área territorial do município é de 546,958 $\mathrm{km}^{2}$, segundo dados do IBGE (2018). O município limita-se ao norte com Bandeira do Sul e Botelhos, a leste Caldas, na porção oeste com Águas da Prata, São Sebastião da Grama, Divinolândia e Caconde, ao Sul com Andradas. (Figura 1).

O censo de 2010 do IBGE informa que a população do município é de 152.435 habitantes, tendo uma densidade demográfica de 278,54 hab. $\mathrm{km}^{2}$. O Índice de Desenvolvimento Humano do município apresenta o percentual de 0,779 , o que configura para uma classificação "alto". Estes dados foram publicados pelo Atlas do Desenvolvimento, no ano de 2010.

O desenvolvimento do município está ligado as indústrias e ao turismo, entre os destaques do turismo estão as águas termais, trazendo muitos turistas do estado de São Paulo e do Rio de Janeiro. Atualmente o setor econômico mais forte é o de serviços (IBGE,2014).

O planalto de Poços de Caldas está inserido no planalto Sul de Minas, que se divide em outras duas compartimentações morfológicas, como a Superfície do Alto Rio Grande e o Planalto de 
São Pedro de Caldas (DNPM,1979). O anel de cristas do planalto de Poços de Caldas tem uma extensão de $800 \mathrm{~km}^{2}$, altitude variável entre 300 a 500 metros acima do relevo cristalino e constituise principalmente por rochas alcalinas, como foiaítos e tinguaítos. (DNPM,1979).

Dada a complexidade altimétrica do Planalto de Poços de Caldas, Moraes e Jiménez-Rueda (2008), dividiram o planalto em cinco classes altimétricas: muito baixos ( 800 a 900 metros), baixos (900 a 1.000 metros), médios (1.000 a 1.200 metros), altos (1.200 a 1.400 metros), muito altos (em categoria superior a 1.400 metros).

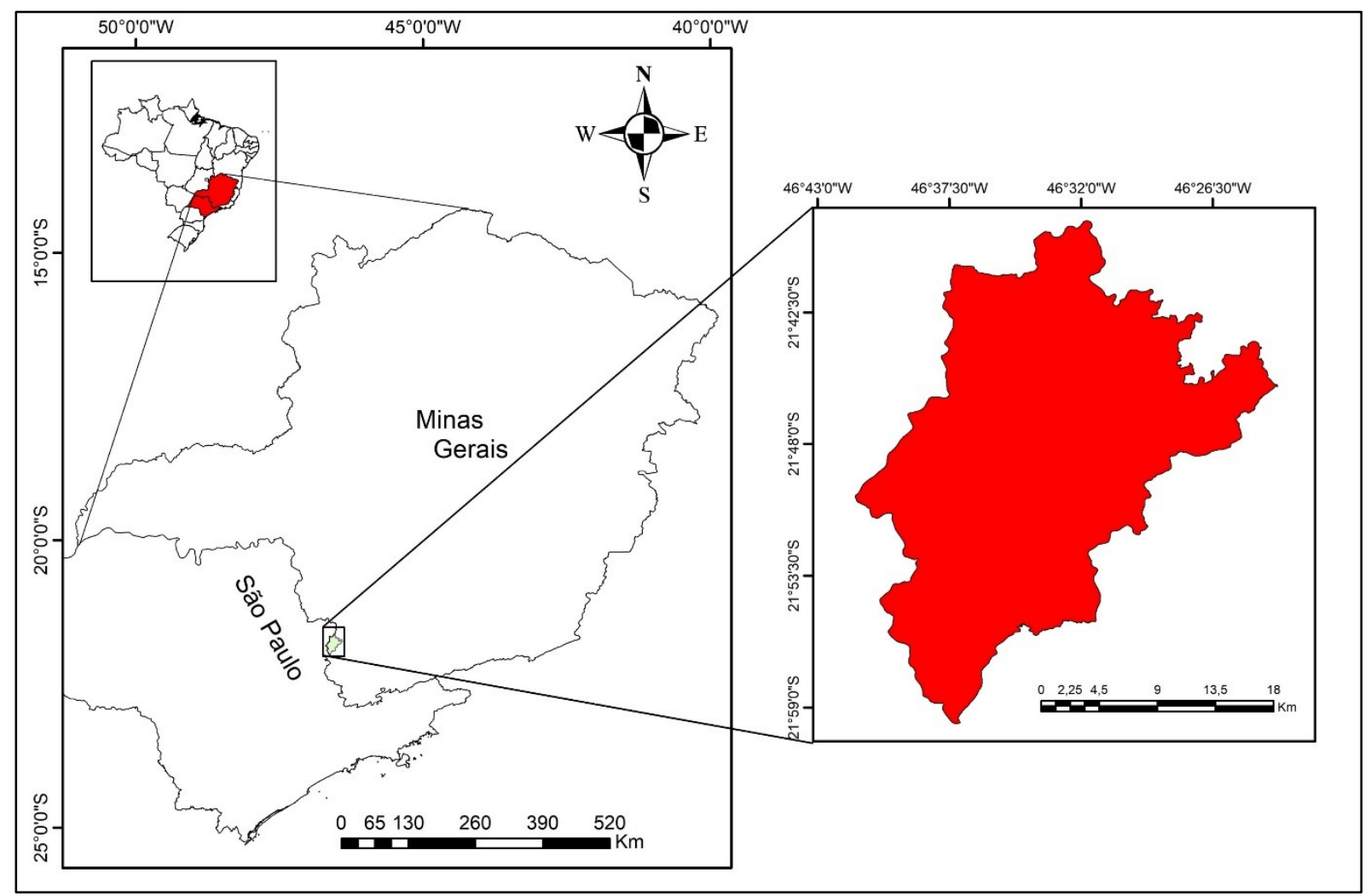

Figura 1 - Localização do município de Poços de Caldas no estado de Minas Gerais.

Fonte: Autor, 2019.

Segundo o Plano Diretor (2006, p. 47), as morfologias apresentadas no município são:

Cristas e Escarpas - Apresentam declives superiores a 40\%, onde ocorrem afloramentos de rochas associados à litossolos e cambissolos, são unidades para a agropecuária devido ao relevo acidentado e solos rasos;

Colinas de Topo Aplainado - Apresentam declives inferiores a 10\%, sendo os topos de morro importantes áreas de recarga de aquíferos freáticos e consideradas áreas de preservação permanente. No Município são utilizadas na cafeicultura, silvicultura, fruticultura, pastagens e extração de bauxita. Apresentam como principal problema a compactação do solo devido ao pisoteio de animais e desmatamento;

Vertentes Ravinadas- O solo é cambissolo, possuindo leito rochoso. São áreas de surgência do aquífero freático. Estas áreas devem ser preservadas como regiões de nascentes de primeira ordem, tendo uso atual ligado à preservação da vegetação nativa e silvicultura. Estas áreas apresentam problemas de queimadas e erosões em sulcos;

Rampas de Colúvio - Estes são os ecossistemas que predominam no município de Poços de Caldas, apresentando aclives inferiores a $20 \%$, formados por colúvios. Suas potencialidades viabilizam o uso do solo para culturas anuais, bianuais e permanentes. Têm relevo ondulado 
e propensão à erosão laminar e em sulco. Seu uso atual está ligado a pastagens, culturas perenes e temporárias;

Terraços e Planícies Fluviais - São as várzeas dos cursos d'água e tem declividade inferior a $3 \%$, sendo constituídas por aluvião. Estas áreas estão sujeitas a inundações, portanto aptas a culturas de entressafra devido ao encharcamento do solo. São desaconselháveis para assentamentos urbanos. Apresentam problemas referentes à extração de argila, supressão da mata ciliar e como consequência o solapamento de margens. Seu uso atual está ligado às culturas anuais, capineiras e pastagens;

Domos- É resultante de arqueamento de extratos sedimentares e recoberto por neossolos e cambissolos, tendo média fertilidade, são solos rasos e em relevo ondulado apresentam aptidão para pastagens natural e formada. Seu uso atual está ligado à vegetação natural e atividade antrópica, como os loteamentos. Os principais problemas apresentados por estas áreas são a erosão laminar e compactação.

Com esta divisão, o planalto possui oscilações bem representativas em seu relevo, sendo destaques de patamares altimétricos mais altos a Serra São Domingos, um dos cartões postais mais visitados do município pelos turistas, além de outros complexos de serras que circunvizinham toda região.

O Clima de Poços de Caldas-MG é classificado como Cwb - mesotérmico, dentro da classificação climática de KÖPPEN (1948), apresentando precipitações que variam de $1300 \mathrm{~mm}$ a $1750 \mathrm{~mm}$ anuais (PMPC, 2006).

O município se insere em uma região vulcânica, tendo sua hidrografia influenciada por sistema de fraturas. Este sistema hídrico é abastecido pelas chuvas, que precipitam no planalto. (IDEM, 2006)

\subsection{Dados Pluviométricos}

Neste estudo foi utilizado tratamento quantitativo dos dados diários de precipitação, disponibilizados pela Companhia Brasileira de Alumínio - CBA e o Departamento Municipal de Água e Esgoto - DMAE. Os dois postos pluviométricos não possuem falhas na série histórica, que se inicia no ano de 2003 e termina no ano de 2018 (Tabela 1).

Tabela 1: Informações sobre os postos pluviométricos do município de Poços de Caldas.

\begin{tabular}{ccccc}
\hline $\begin{array}{c}\text { ORGÃO } \\
\text { RESPONSÁVEL }\end{array}$ & LATITUDE & LONGITUDE & ALTITUDE & SÉRIE HISTÓRICA \\
\hline CBA & $\mathrm{S} 21^{\circ} 49^{\prime}$ & W 46 $38^{\prime}$ & 1255 metros & $2003-2015$ \\
DMAE & $\mathrm{S} 21^{\circ} 50^{\prime}$ & ${\mathrm{W} 46^{\circ} 36^{\prime}}_{1255 \text { metros }}$ & $2016-2018$ \\
\hline
\end{tabular}

Fonte: Dados da CBA e DMAE.

Na Tabela 2 são apresentados os totais mensais de precipitação da série temporal (20032018), formatado no software Excel, mediante a soma dos totais mensais de cada mês. Os três útimos anos da série apresentam os dados disponibilizados pelo DMAE enquanto os demais dados são fornecidos pela CBA. 
A distribuição espacial dos dois postos pluviométricos está alocada na porção Sul e Oeste do município. A distância entre os postos é de 3,57 Km (Figura 2) com diferença latitudinal e longitudinal de apenas um e dois minutos respectivamente. Por enquanto localizam-se fora da mancha urbana do município que prossegue em franca expansão em uma mesma altitude, garantindo assim a compatibilidade dos dados para o uso sequencial na série histórica.

Tabela 2: Dados mensais da série histórica (2003-2018) do município de Poços de Caldas - MG.

\begin{tabular}{|l|c|c|c|c|c|c|c|c|c|c|c|c|c|c|c|}
\hline Ano Janeiro & Fevereiro Março & Abril & Maio & Junho & Julho & Agosto & Setembro & Outubro & Novembro & Dezembro & Total Anual \\
\hline 2003 & 456,0 & 179,0 & 188,0 & 130,0 & 81,0 & 0,0 & 14,0 & 12,0 & 7,0 & 114,0 & 212,0 & 327,0 & 1720,0 \\
\hline 2004 & 342,0 & 491,0 & 101,0 & 143,0 & 247,0 & 44,0 & 39,0 & 8,0 & 28,0 & 159,0 & 188,0 & 316,0 & 2106,0 \\
\hline 2005 & 483,0 & 171,0 & 290,0 & 51,0 & 127,0 & 33,0 & 33,0 & 3,0 & 121,0 & 137,0 & 134,0 & 231,0 & 1814,0 \\
\hline 2006 & 336,0 & 262,0 & 240,0 & 96,0 & 3,0 & 7,0 & 7,0 & 35,7 & 62,0 & 201,3 & 239,9 & 328,7 & 1818,6 \\
\hline 2007 & 603,8 & 247,0 & 177,1 & 170,9 & 79,4 & 13,6 & 132,3 & 0,0 & 5,0 & 97,5 & 234,2 & 303,5 & 2064,3 \\
\hline 2008 & 382,4 & 97,5 & 234,6 & 145,2 & 63,2 & 16,6 & 0,0 & 41,6 & 83,8 & 180,3 & 231,8 & 300,0 & 1777,0 \\
\hline 2009 & 366,8 & 325,6 & 162,7 & 85,4 & 62,9 & 77,2 & 64,6 & 130,5 & 234,8 & 238,4 & 228,8 & 394,8 & 2372,5 \\
\hline 2010 & 311,0 & 164,0 & 131,3 & 55,6 & 18,2 & 33,4 & 18,0 & 0,0 & 102,4 & 135,5 & 238,7 & 361,9 & 1570,0 \\
\hline 2011 & 413,9 & 202,4 & 294,0 & 151,5 & 13,0 & 38,0 & 0,0 & 25,0 & 17,0 & 233,0 & 293,0 & 252,0 & 1932,8 \\
\hline 2012 & 274,7 & 100,5 & 148,0 & 153,0 & 96,0 & 113,0 & 52,0 & 0,0 & 21,0 & 116,0 & 275,5 & 380,5 & 1730,2 \\
\hline 2013 & 493,0 & 295,0 & 226,0 & 85,0 & 107,0 & 35,0 & 52,3 & 6,0 & 79,0 & 114,7 & 241,9 & 346,8 & 2081,7 \\
\hline 2014 & 96 & 46 & 165 & 126 & 52 & 9 & 91 & 4 & 96 & 45 & 256 & 229 & 1214 \\
\hline 2015 & 73 & 132 & 175,5 & 34 & 57,5 & 29,05 & 10 & 0 & 61 & 77,5 & 166,19 & 229,5 & 1045,2 \\
\hline 2016 & 445 & 277 & 201,5 & 3,55 & 75,5 & 129 & 0 & 54,5 & 7,5 & 129 & 187,05 & 139,5 & 1649,1 \\
\hline 2017 & 358,13 & 142,05 & 238,03 & 72 & 97,5 & 37,5 & 2,5 & 25 & 0 & 74,5 & 320,5 & 111,5 & 1479,2 \\
\hline 2018 & 265,5 & 192 & 199 & 8,05 & 32 & 5 & 2 & 31 & 67,7 & 211,5 & 240 & 226 & 1479,8 \\
\hline & & & & & & & & & & & & & \\
\hline & & & & & & & & & & Legenda: & Posto pluviométrico CBA & \\
\hline & & & & & & & & & & & Posto pluviométrico DMAE & \\
\hline
\end{tabular}

Fonte: Dados da CBA e DMAE.

\section{Mapa de Localização dos Postos Pluviométricos no município de Poços de Caldas - MG}

P1

CBA Companhia Brasileira de Alumínio

P2

Q ETAVDMAE

Distância entre os

postos: $3,57 \mathrm{KM}$.

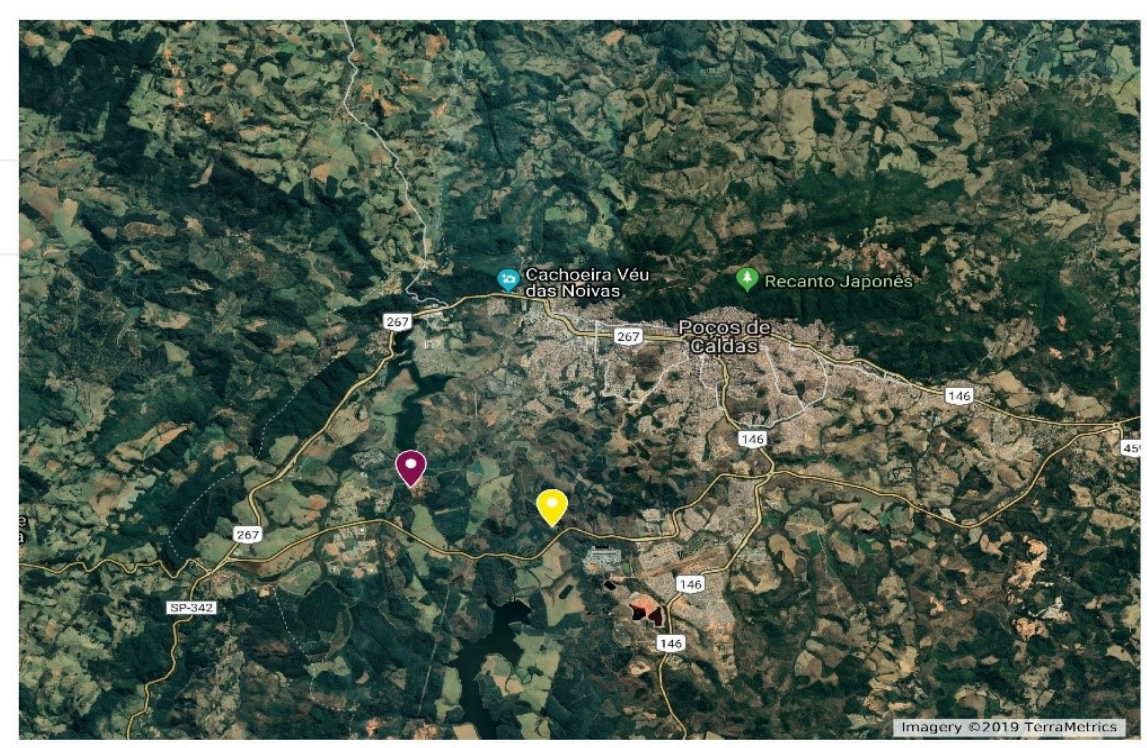

Figura 2 - Mapa de localização dos postos pluviométricos no município de Poços de Caldas - MG. Fonte: Elaborado pelo autor, usando do Google Maps. 


\subsection{Análise dos dados}

$\mathrm{Na}$ análise pluviométrica foi realizado tratamento estatístico dos dados coletados, com o intuito de extrair o máximo de informações na série anual e mensal, qualificando assim a análise desenvolvida.

A análise da série histórica (2003-2018) foi feita mediante a metodologia de Anos-Padrão, que classifica e caracteriza o comportamento pluviométrico ao longo da série.

O desvio padrão é utilizado para entender os desvios em $(\mathrm{mm})$ da série histórica, seja ela positiva ou negativa, baseando-se na média da precipitação do período analisado no estudo. Com esta metodologia, ficam claras as oscilações das precipitações, ajudando assim, a qualificar a análise dos dados pluviométricos.

A caracterização se pauta nos "diferentes graus de proximidade do ritmo habitual ao lado daqueles afetados por irregularidades na circulação" (MONTEIRO, 1991, p.39).

No período de análise foram avaliados os padrões habituais ou normais e as excepcionalidades, obtidas pela média anual e os desvios padrões, que fornecem categorias qualitativas do comportamento pluviométrico do período em estudo, colaborando também na classificação de anos extremos (Tabela 3).

Tabela 3: Classificação de anos-padrão, segundo SANT’ANNA (1995).

\begin{tabular}{cccc}
\hline Classificação & Padrões Pluviométricos & Siglas & Desvio (+) ou (-) em \% \\
\hline \multirow{2}{*}{ Anos Secos } & Extremamente Seco & (S) & $<30 \%$ \\
& Tendente a seco & (TS) & $15-30 \%$ \\
\multirow{2}{*}{ Anos Normais } & Normal levemente tendente a seco & (NTS) & $5-15 \%$ \\
& Normal & (N) & $0-5 \%$ \\
\multirow{2}{*}{ Anos Chuvosos } & Normal levemente tendente a chuvoso & (NTC) & $5-15 \%$ \\
& Tendente a chuvoso & (TC) & $15-30 \%$ \\
\hline
\end{tabular}

Fonte: Adaptado de SANT'ANNA (1995).

\section{4- RESULTADOS}

\subsection{Variabilidade Pluviométrica}

A definição do ano padrão auxiliou na caracterização do comportamento pluviométrico do município de Poços de Caldas-MG, com isto, foi possível apontar os anos extremos, ou seja, anos atípicos ao período de análise, sejam eles, mais chuvosos ou mais secos. Na análise da média mensal foi verificado que o mês de janeiro apresenta a maior média mensal, ultrapassando os $300 \mathrm{~mm}$, e o mês de agosto as médias mais baixas, aproximadamente $23 \mathrm{~mm}$ (Figura 3). A representação mostra de forma bem clara que o verão é chuvoso e o inverno seco. 


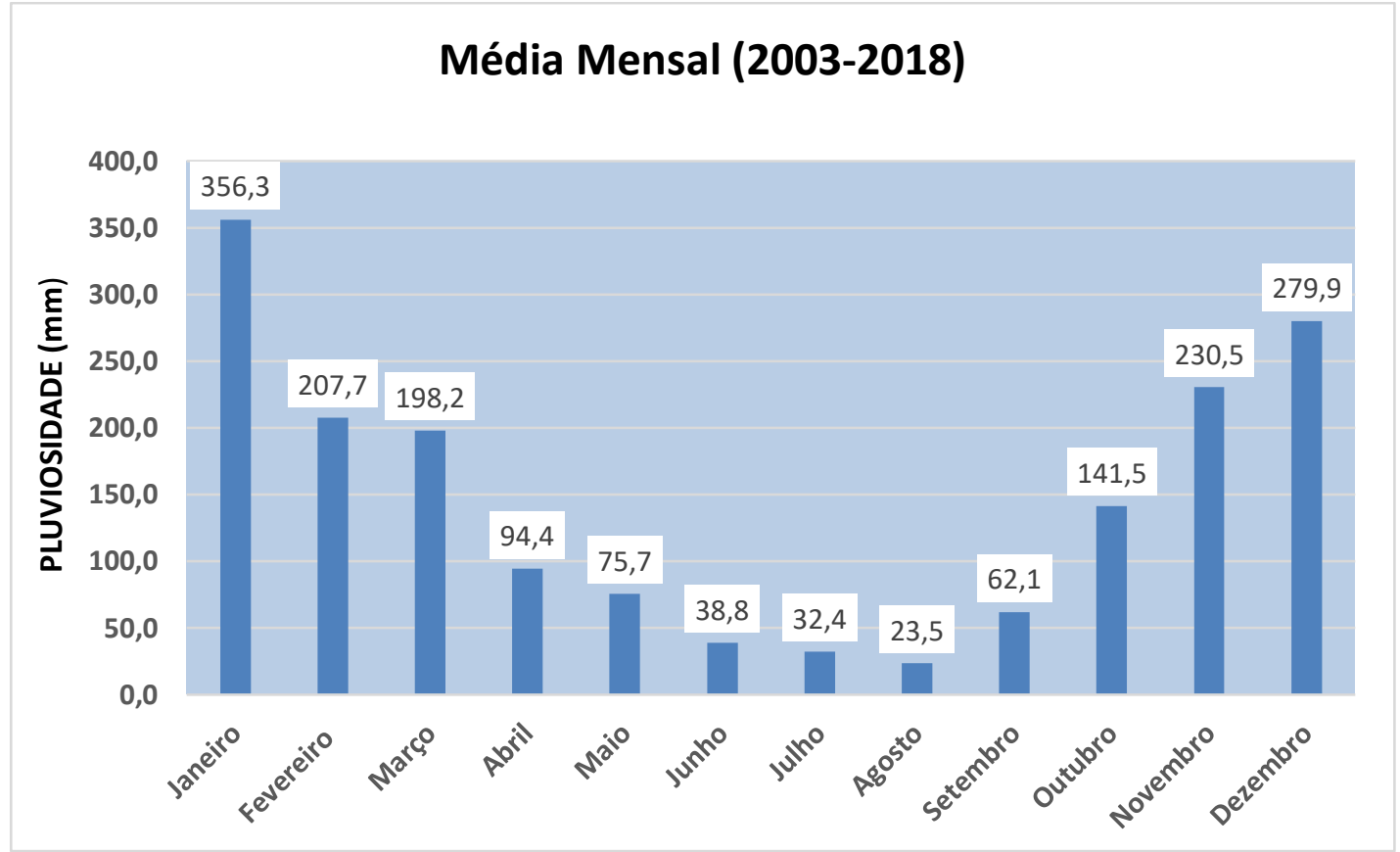

Figura 3 - Média mensal de pluviosidade em Poços de Caldas - MG (2003 - 2018) Fonte: Elaborado pelo autor.

O desvio padrão na série histórica, apresenta 8 anos positivos e 8 negativos (Figura 4), sendo os maiores desvios positivos os anos de 2009 e 2004 e os desvios negativos mais destacados os anos de 2015 e 2014, evidenciando um evento atípico nos mesmos.

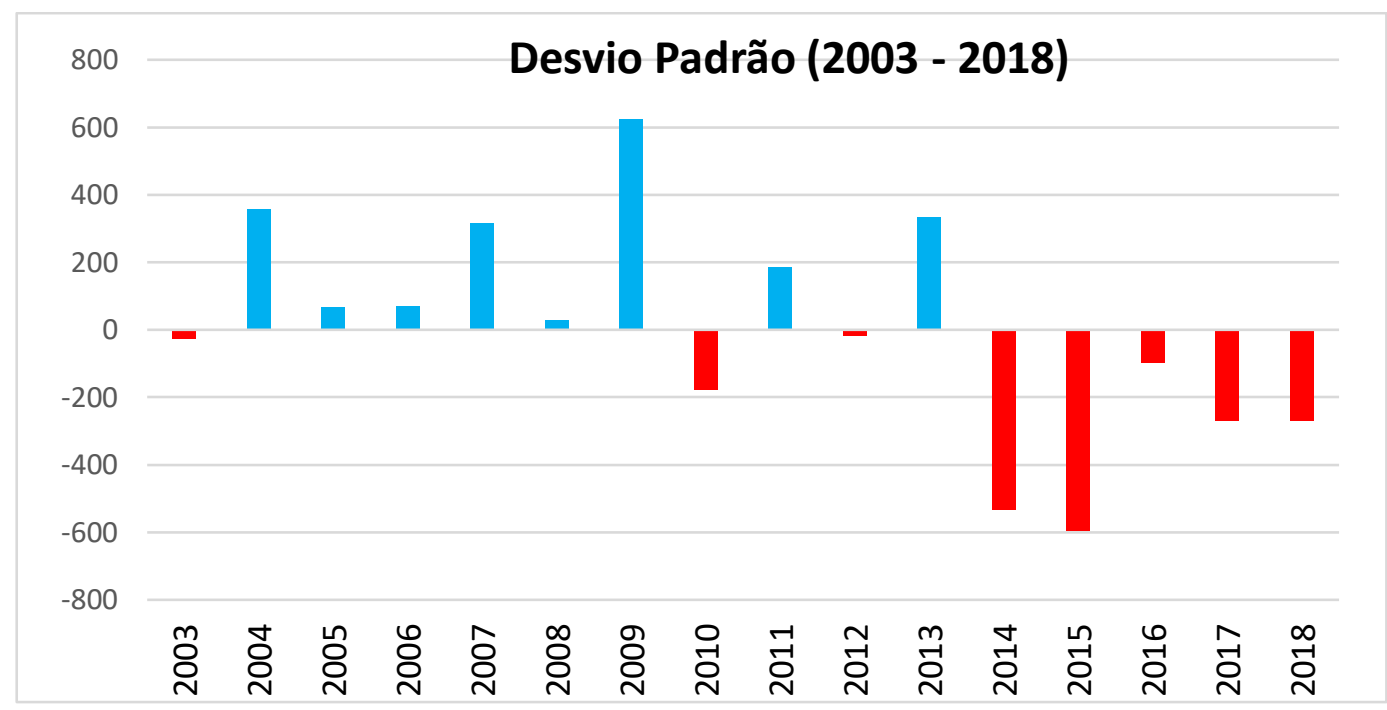

Figura 4 - Desvio em relação à média dos dados pluviométricos registrados no posto pluviométrico da CBA e do DMAE em (mm) entre 2003-2018.

Fonte: Elaborado pelo autor.

Segundo o método para o cálculo do desvio padrão foi gerada a

Tabela 4, referente às precipitações de Poços de Caldas, com uma predominância de anos habituais ou normais (N, NTC e NTS), sendo eles os anos de 2003, 2005, 2006, 2008, 2010, 2011, 2012, 2016, ou seja, totalizando 50\% dos anos da série temporal. 
Tabela 4: Classificação dos Anos Padrão do município de Poços de Caldas (2003 - 2018).

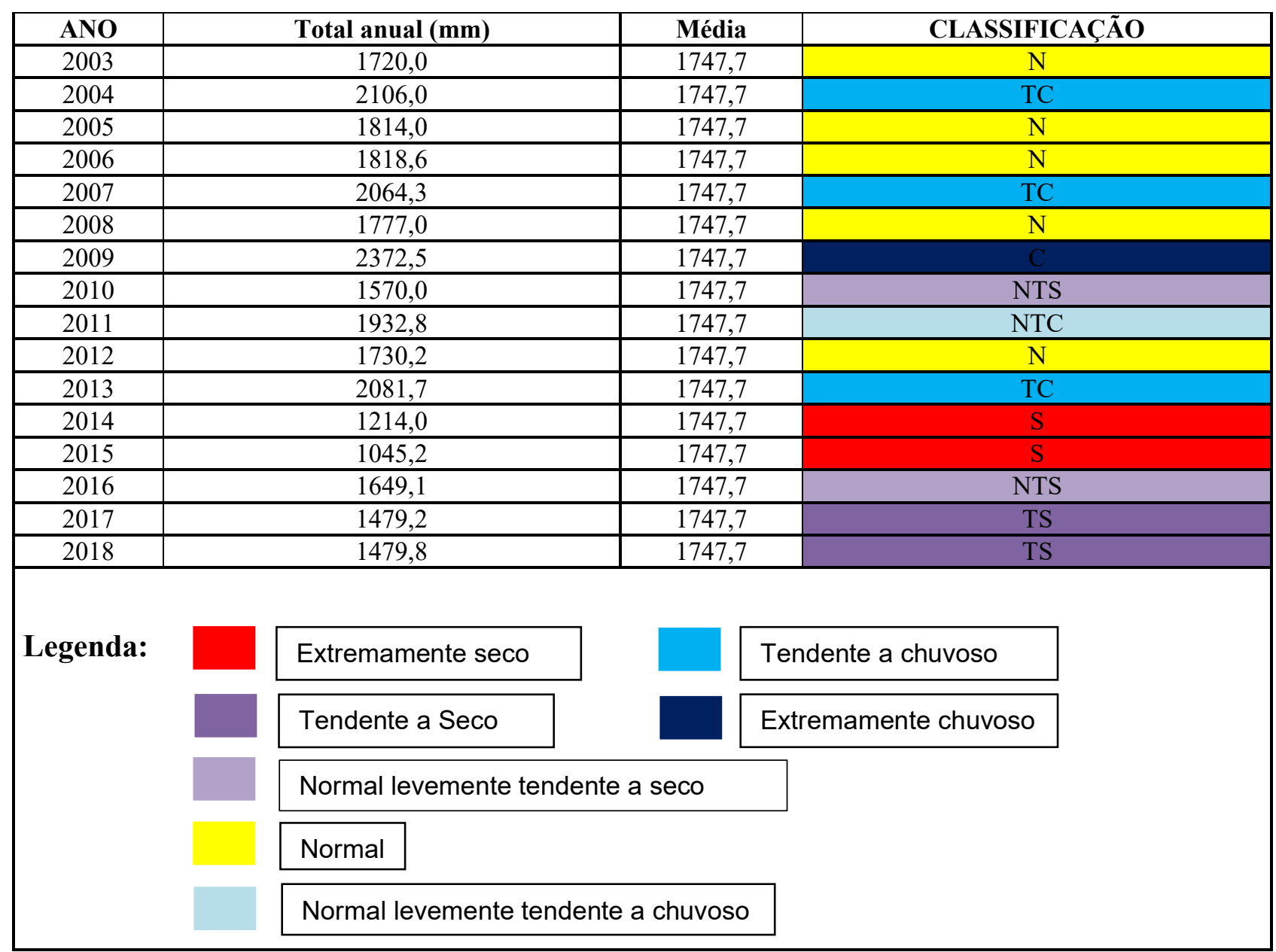

Fonte: Elaborado pelo autor.

No enquadramento de classe de anos excepcionais (TC, TS, S e C), tem-se as classes de anos chuvosos representadas pelos anos de 2004, 2007, 2009 e 2013, enquanto os anos secos foram representados pelos anos de 2014,2015,2017 e 2018, totalizando juntos 50\% da série temporal.

A Tabela 4 deixa claro o padrão de precipitação habitual ou normal $(\mathrm{N})$, mostrando que os valores são bem próximos da média, evidenciada na tabela 5, onde aponta que 31,25\% é considerado ano padrão $(\mathrm{N})$, dentro da série histórica em análise. As classes transitórias, correspondem a classificação tendente a seco (TS) e tendente a chuvoso (TC), preenchendo 31,25\% da série histórica, restando para as classes extremas, (C) chuvosa e (S) seco o percentual de 18,75\% na série histórica em análise. Nesta série verifica-se o predomínio da habitualidade frente aos eventos extremos.

Os números apontam para uma maior ocorrência da classe normal $(\mathrm{N})$ na série histórica, demonstrando um comportamento pluviométrico próximo do ideal, aproximado da média anual da série histórica e indicando predomínio da habitualidade. A classes "tendente a chuvoso" e "tendente a seco", expressam um comportamento relevante na série histórica, mostrando que há a presença de uma configuração de precipitação intermediária na área de estudo. As classes "extremamente seco" 
e "extremamente chuvoso" compõem uma pequena parcela na série histórica, sendo um no ano de 2009, configurando como extremamente chuvoso e dois no ano de 2014 e 2015, configurando como extremamente seco. A Tabela 5 apresenta a frequência de ocorrência das classes de precipitação da série histórica $(2003$ - 2018)

Os anos representativos foram selecionados mediantes a média anual e o desvio padrão. Os anos em destaque na Tabela 6 mostram os anos padrões que representam a série histórica de 16 anos para o município de Poços de Caldas. (Tabela 6)

Tabela 5: Número de ocorrências das classes pluviométricas na série histórica no município de Poços de Caldas - MG $(2003-2018)$.

\begin{tabular}{cccc}
\hline Classes & $\begin{array}{c}\text { Número de } \\
\text { ocorrências }\end{array}$ & $\%$ & Colocação \\
\hline S & $2 \mathrm{x}$ & 12,50 & $3^{\circ}$ \\
TS & $2 \mathrm{x}$ & 12,50 & $3^{\circ}$ \\
NTS & $2 \mathrm{x}$ & 12,50 & $3^{\circ}$ \\
N & $5 \mathrm{x}$ & 31,25 & $1^{\circ}$ \\
NTC & $1 \mathrm{x}$ & 6,25 & $4^{\circ}$ \\
TC & $3 \mathrm{X}$ & 18,75 & $2^{\circ}$ \\
C & $1 \mathrm{X}$ & 6,25 & $4^{\circ}$ \\
\hline
\end{tabular}

Fonte: Elaborada pelo autor

Tabela 6: Anos representativos das classes pluviométricas na série histórica no município de Poços de Caldas - MG $(2003-2018)$.

\begin{tabular}{cccc}
\hline Período & CHUVOSO (2009) & NORMAL (2012) & SECO (2015) \\
\hline Anual & 2362,5 & 1777,2 & 1045,2 \\
\hline
\end{tabular}

Fonte: Elaborado pelo autor.

Conforme é possível observar através destas tabelas, sem a análise dos dados e seu tratamento fica difícil obter um entendimento maior dos padrões atmosféricos de uma determinada área e se prevalece um período de incertezas diante do ritmo da série ou se prevalece ainda um quadro de habitualidade que manifesta um equilíbrio no sistema que deve ser preservado ao máximo naquilo que tange ao controle das ações antrópicas que impactam sobre os domínios da atmosfera, sobretudo aquelas que compreendem a alteração do albedo da superfície ou a alteração da composição gasosa da atmosfera terrestre.

\section{CONSIDERAÇÕES FINAIS}

No decorrer da análise, exposta nas páginas anteriores, é possível observar alguns aspectos interessantes sobre a precipitação na escala de análise, assim ajudando a compreender o comportamento pluviométrico na área de estudo, além de estimular futuros estudos na área e na 
temática, já que é uma região com poucos estudos com temática climática devido as falhas e baixo número de pluviômetros - dados disponíveis.

A média anual da série histórica é $1.747,7 \mathrm{~mm}$, demonstra que a área em estudo possui um regime pluviométrico expressivo e relevante. Mesmo com esta média anual alta, apareceu na série histórica anos oscilantes, como o caso do ano de 2009, onde a precipitação foi 35,7\% acima da média. Outro exemplo desta oscilação foi o ano de 2015, onde a precipitação ficou bem abaixo da média anual da série histórica, precipitando $40 \%$ abaixo da média, estes anos foram escolhidos como ano padrão extremamente chuvoso e extremamente seco, respectivamente.

Entre os resultados a destacar, ficou explicito durante a análise, a configuração de dois comportamentos pluviométricos, sendo o primeiro com constância pluviométrica, ou seja, há uma tendência de pluviosidade e o outro com oscilação, expostos neste estudo como os anos extremos, geralmente relacionados a eventos de chuva ou seca.

Com este estudo, tem-se um padrão de variabilidade de precipitação no município de Poços de Caldas, ajudando a entender os comportamentos pluviométricos da área de estudo, mediante a análise de 2 postos pluviométricos em uma série temporal composta por 16 anos.

É importante citar a dificuldade de se obter os dados de precipitação para a construção do estudo, dado ao baixo número de postos pluviométricos distribuídos no município. Outra dificuldade encontrada no estudo foram as falhas nas séries temporais, dificultando o prosseguimento das análises, que posteriormente foram sanados com a utilização de dois postos pluviométricos, que não apresentavam falhas ou lacunas nos dados pluviométricos. O fator positivo foi a disponibilidade dos postos pluviométricos estarem na mesma região climática, o que possibilitou o prosseguimento do estudo sem o comprometimento da série.

Neste estudo ficou claro o comportamento pluviométrico do município de Poços de CaldasMG na série histórica de 16 anos. Um dos pontos mais cruciais foi constatar que há uma habitualidade na precipitação, ou seja, os padrões são mais próximos da média histórica, quase não havendo muitos eventos extremos, salvo os anos de 2009, 2014 e 2015, que apresentaram oscilações pluviométricas, configurando assim um ano extremamente chuvoso em 2009, com a precipitação anual chegando em 2.372,5 mm e dois anos extremamente secos em 2014 e 2015, com a precipitação variando entre 1045,2 a 1214,0 mm, apresentando assim 3 eventos extremos na série histórica de 16 anos no município de Poços de Caldas-MG.

Fica evidente a importância da Climatologia nos estudos de variabilidade climática, já que auxilia as esferas públicas a se planejarem de acordo com o comportamento climático, além de ajudar a criar uma modelagem, possibilitando prevenir as ocorrências extremas da natureza, como inundações, deslizamentos ou secas extremas. 
Em face de toda discussão contemporânea em voga no país acerca da credibilidade ou não da Ciência, cumpre registrar ao final desse artigo a relevância que possui o investimento público no Ensino e Pesquisa, pois, não obstante ao dinamismo econômico que se observa na área de estudo e sua relevância frente ao contexto do Sul de Minas Gerais, fica notória, pela pobreza de dados disponíveis para análise o prejuízo que a ausência de uma Universidade ou Instituto de Pesquisa causou para o município, dificultando ações acadêmicas que possam contribuir com o equacionamento de seus problemas e a elaboração de um plano de gestão para o presente que se desdobre no futuro em benefício da sociedade e meio ambiente.

\section{REFERÊNCIAS}

ALBERTI, H. L. C. Caracterização fisiográfica e avaliação hidrológica na bacia do Ribeirão das Antas, Planalto de Poços de Caldas, MG. 2008. 89 f. Dissertação (Mestrado em Geografia) Instituto de Geociências, Universidade Estadual de Campinas, Campinas, 2008.

ARAÚJO, A; GUETTER, A. Avaliação hidrológica da técnica CMORPH de estimativa de chuva por satélite sobre a bacia do Iguaçu. In: SIMPÓSIO BRASILEIRO DE RECURSOS HÍDRICOS. 16., 2005. João Pessoa. Anais... João Pessoa: SBRH, 2005.

ATAÍDE, K. R. P.; LEDO, I. D.; OLIVEIRA, M. G. R.; BEZERRA, W. A. Avaliação da estimativa da temperatura de superfície obtida pelo sensor MODIS para o estado de Goiás. In: SIMPÓSIO BRASILEIRO DE SENSORIAMENTO REMOTO. 14., Natal. Anais... Natal: INPE, 2009. p. 34953502.

ATLAS BRASIL. Poços de Caldas, MG - IDHM. Disponível em: http://atlasbrasil.org.br/2013 /pt/perfil_m/pocos-de-caldas_mg. Acesso em: 28 mai. 2019

BARROS, H. R.; LOMBARDO, M. A. A ilha de calor urbana e o uso e cobertura do solo em São Paulo-SP. Geousp - Espaço e Tempo (Online), v. 20, n. 1, p. 160-177, 2016.

BRASIL - DEPARTAMENTO NACIONAL DA PRODUÇÃO MINERAL. Projeto Sapucaí, Estado de São Paulo, Rio de Janeiro e Minas Gerais: relatório final de geologia, por Quirino Koefer e outros. Brasília, DNPM/CPRM, 1979. 299p.

CONTI, G. N. Estimativa da precipitação através de técnicas de sensoriamento remoto: Estudo de caso para o estado do Rio Grande do Sul. 2002. 205 f. Dissertação (Mestrado em Engenharia de Recursos Hídricos e Saneamento Básico) - Instituto de Pesquisas Hidráulicas, Universidade Federal do Rio Grande do Sul, Porto Alegre, 2002.

FARIAS, H. S.; ALVES, G. F. S. Caracterização Espacial e Temporal da Precipitação na Costa Verde Fluminense - 2001 a 2016. Geo UERJ, Rio de Janeiro, n. 34, p. 1-24, 2019.

IBGE. Banco de dados: o Brasil município por município. 2014. IBGE Cidades. Disponível em: https://cidades.ibge.gov.br/. Acesso em: 25 mai. 2019.

INSTITUTO NACIONAL DE METEOROLOGIA - INMET. Normais Climatológicas. 1999. Disponível em: http://www.inmet.gov.br/portal/index.php?r=clima. Acesso em: 29 set. 2019 
MONTEIRO, C.A.F. O clima e a organização do espaço no Estado de São Paulo: problemas e perspectivas. Série Teses e Monografias, nº 28. São Paulo: USP/IGEOG, 1976. 54p.

MONTEIRO, C. A. F. Clima e exepcionalismo: conjecturas sobre o desempenho da atmosfera como fenômeno geográfico. 1. ed. Florianópolis: Ed. da UFSC, 1991. 233p.

MORAES, F. T.; JIMÉNEZ-RUEDA, F. R. Fisiografia da região do planalto de Poços de Caldas, MG/SP. Revista Brasileira de Geociências, São Paulo, v. 38, n. 1, p. 196-208, 2008.

NASCIMENTO, D. T. F.; NETO, J. M. S.; NUNES, L. C. Definição dos anos-padrão para o estudo da pluviometria do Estado de Goiás e do Distrito Federal. Brazilian Geographical Journal: Geosciences and Humanities research medium, Ituiutaba, v. 6, n. 1, p. 272-290, 2015.

NEVES, D. G.; CUNHA, A. C.; SOUZA, E. B.; BARRETO, N. J. C. Modelagem climática regional durante dois anos de extremos de precipitação sobre o estado do Amapá: teste de sensibilidade aos esquemas convectivos. Revista Brasileira de Meteorologia, São Paulo, v. 26, n. 4, p. 569-578, 2011.

POÇOS DE CALDAS. Câmara Municipal. Documento de 2002, revisado em 2006, de acordo com a lei federal 10.257/10). Prefeitura Municipal de Poços de Caldas, Secretaria de planejamento e coordenação. 2006. Poços de Caldas: PMPC. Disponível em: http://www.pocosdecaldas.mg.leg.br/ Acesso em: 21 set. 2019.

TAVARES, A. C. Critérios de escolha de anos padrões para análise rítmica. Geografia, Rio Claro, v. 1, n. 1, p. $79-87,1976$.

SANT'ANNA NETO, J. L. A tendência das chuvas no estado de São Paulo: uma contribuição aos estudos sobre as mudanças climáticas regionais nos últimos 100 anos. Researchgate.net. p. 1-10. Disponível em: https://www.researchgate.net/profile/2677.pdf . Acesso em: 22 abr. 2019.

OGASHAWARA, I. Análise rítmica e a climatologia geográfica brasileira. Revista Eletrônica Geoaraguaia, Barra do Garças, v. 2, n. 2, p.57-72, 2012.

SANTOS, B. C.; SOUZA, P. H.; VECCHIA, F. A. S. A caracterização da precipitação do ano hidrológico de 2013-2014 na região de São Carlos/SP e sua repercussão no espaço geográfico. Revista Brasileira de Climatologia, v. 21, p. 136-152, 2019.

SOUZA, D. O.; OliveirA, F. G., CASTRO, I. L.; SOARES, J. B. S.; REIS, M. M. R., FIGUEIREDO, F. P. Frequência de ocorrência de precipitação pluviométrica em Montes Claros-MG. Agrarian, v. 11, n. 42, p. 337-342, 2018.

SOUZA, P. H.; SANCHES, R. G.; SANTOS, B. C. O estudo do comportamento da temperatura em Machado/MG entre 1991 e 2017 e a influência exercida pela precipitação sazonal nesse processo. Caderno de Geografia, Belo Horizonte, v. 29, p. 213-244, 2019.

SCHNEIDER, H.; SILVA, C. A.; SANTOS, V. A. A escolha de anos padrão como base para identificação do regime das chuvas na porção centro sul de Mato Grosso do Sul. Revista Geonorte, Edição Especial 2, v. 1, n. 5, p. 262-270, 2012.

XAVIER, T. M. B. S.; SILVA, J. F.; REBELLO, E. R. A Técnica dos Quantis e suas aplicações em Meteorologia, Climatologia, Hidrologia, com ênfase para as regiões brasileiras. Brasília: Ed. Thesaurus, 2002. 140p. 